Running head: REGULATORY FOCUS AND ECONOMIC INTERDEPENDENCE

Regulatory Focus and Interdependent Economic Decision-Making

Jun $\mathrm{Gu}$

University of British Columbia

Geoffrey J. Leonardelli

University of Toronto

Word count: 4999 (text + footnotes)

Author Note.

This work was supported by a Michael Lee Chin Institute for Global Citizenship research grant and a Canadian SSHRC grant to the third author. We thank David De Cremer, Joe Magee, and David Messick for commenting on an earlier draft, Paul van Lange for his ring measure materials, Kris Preacher for statistics advice, and members of the Self and Identity Lab (SAIL) for their ongoing research commentaries. Correspondence should be addressed to Jun $\mathrm{Gu}$ (Jun.gu@sauder.ubc.ca), Sauder School of Business, University of British Columbia, 2053 Main Mall, Vancouver, BC Canada V6T 1Z2, Canada.

Reference:

Gu, J., Bohns, V., \& Leonardelli, G.J. (in press). Regulatory focus and interdependent economic decision-making. Journal of Experimental Social Psychology. 


\begin{abstract}
Traditional theories of self-interest cannot predict when individuals pursue relative and absolute economic outcomes in interdependent decision-making, but we argue that regulatory focus (Higgins, 1997) can. We propose that a concern with security (prevention focus) motivates concerns with social status, leading to the regulation of relative economic outcomes, but a concern with growth (promotion focus) motivates the maximization of opportunities, leading to a focus on absolute outcomes. Two studies supported our predictions; regardless of prosocial or proself motivations, a promotion focus yielded greater concern with absolute outcomes, but a prevention focus yielded greater concern with relative outcomes. Also, Study 3 revealed that a prevention focus led to a greater rejection of a negative relative but positive absolute outcome in an ultimatum game because of concerns with status. This research reveals that apparently opposing orientations to interdependence - equality and relative gain - serve the same selfregulatory purpose: the establishment of security.
\end{abstract}

Words: 149

Keywords: regulatory focus, economic outcomes, relative value, absolute value, interdependence, social orientations 


\section{Regulatory Focus and Interdependent Economic Decision-Making}

The economics literature largely assumes that individuals seek to maximize absolute economic outcomes. As John Stuart Mill (1874/1968) asserted, individuals generally pursue "the greatest amount of necessaries, conveniences, and luxuries" (p. 144). From this perspective, deviations from maximizing absolute outcomes are irrational and non-normative. Yet strikingly, since the first empirical demonstrations (Messick \& Thorngate, 1967; Stouffer, Schuman, DeVinney, Star, \& Williams, 1949), evidence has established that individuals also seek to regulate relative economic outcomes (i.e., the difference between their and others' outcomes; e.g., Loewenstein, Thompson, \& Bazerman, 1989; Messick \& McClintock, 1968), and that relative

outcomes may have important consequences for individual well-being (Oishi, Kesebir, \& Diener, 2011). Although current motivational theories of interdependent decision-making can explain the pursuit of absolute outcomes by determining degree of self-interest (Siegel \& Fouraker, 1960), self-versus-shared interest (Deutsch, 1973), or a combination of these perspectives (Carnevale \& De Dreu, 2006; Pruitt \& Rubin, 1986), they cannot explain the pursuit of relative outcomes. This paper offers an explanation for this phenomenon using regulatory focus theory - i.e., a theory of how individuals approach self-interest.

Regulatory focus theory (Higgins, 1997; see Scholer \& Higgins, 2011 for a recent review) distinguishes between two approaches to a goal: focusing on security and minimizing negative outcomes (a prevention focus) or focusing on growth and maximizing positive outcomes (a promotion focus). Regulatory focus has been shown to affect a wide variety of outcomes, including self-motivation (e.g., Leonardelli \& Lakin, 2010; Leonardelli, Lakin, \& Lakin, 2007), decision-making (e.g., Brockner, Paruchuri, Idson, \& Higgins, 2002; Liberman, Idson, Camacho, \& Higgins, 1999), and social interaction and interdependence (e.g., Bohns et al., in press; 
Sassenberg \& Woltin, 2008; Shah, Brazy, \& Higgins, 2004; Trawalter \& Richeson, 2006). More importantly, for our purposes, it affects interdependent economic decision-making: in negotiations, a promotion compared to prevention focus led negotiators to set higher aspirations, negotiate more aggressively, and achieve better joint and personal outcomes (Galinsky, Leonardelli, Okhuysen, \& Mussweiler, 2005).

From the lens of existing theories on self-interest, it is tempting to conclude from Galinsky et al.'s (2005) data that a prevention focus leads to a greater "prosocial" than "proself" orientation (Deutsch, 1973) or a weaker motivation for self-interest (Siegel \& Fouraker, 1960). However, this paper offers an alternative perspective: regulatory focus affects the kinds of economic outcomes (i.e., absolute or relative) individuals pursue. Building on research on regulatory focus and goal pursuit (e.g., Crowe \& Higgins, 1997; Friedman, 1999), we argue that a promotion focus motivates decision-makers to maximize absolute economic outcomes, but a prevention focus motivates them to consider relative outcomes.

\section{Independent versus Interdependent Economic Decision-Making}

Imagine a person is given a choice between receiving $\$ 8$ or $\$ 10$. Which would she choose? In this decision, there is only one type of economic metric available: absolute outcomes. Economics theories suggest that rational people invariably choose $\$ 10$, because it provides access to more resources, goods, and opportunities (DeVoe \& Iyengar, 2010).

Now imagine the person is given a choice between an outcome where she and another person each receives $\$ 8$ and an outcome where she receives $\$ 10$ but the other person receives $\$ 12$. Here she can consider multiple pieces of information: her absolute outcomes, the other person's outcomes, and the outcome differences between the two parties. Although classical theories of self-interest (e.g., Hamner \& Harnett, 1975; Mill, 1874/1968; Siegel \& Fouraker, 
1960) argue that individuals are primarily concerned with maximizing their own (and at times others') absolute outcomes, psychological and sociological research has consistently demonstrated that individuals also consider relative outcomes in interdependent decisions like the one above. For example, individuals strongly reject negative relative outcomes (Loewenstein et al., 1989; Crosby, 1976; Guth, Schmittberger, \& Schwarze, 1982; Stouffer et al., 1949) and try to establish relative advantage (Messick \& McClintock, 1968; Eek \& Garling, 2006; Knight \& Dubro, 1984; Snidal, 1991; Waltz, 1979). Psychological theories—including social comparison theory (Festinger, 1954; Suls \& Wheeler, 2000), social identity theory (Tajfel \& Turner, 1986; Turner, 1975; see also Scheepers, Spears, Doosje, \& Manstead, 2006), and equity theory (Adams, 1965) - tend to converge on a common explanation that relative outcomes provide value via social status (i.e., a perception that one is better, more important, and more valuable than others). In order to secure social status, individuals may sacrifice absolute outcomes for relative outcomes.

Overall, past research reveals that people consider both absolute and relative outcomes in making interdependent economic decisions. We argue that individuals' preference for one type of outcome versus the other can be predicted by regulatory focus theory.

\section{Regulatory Focus and Interdependent Economic Decision-Making}

Returning to the simple decision between receiving $\$ 8$ and $\$ 10$, how might regulatory focus affect this decision? It should not. Outside interdependent contexts, promotion and prevention focus should result in a preference for $\$ 10$, whether one views $\$ 10$ as a $\$ 2$ gain over $\$ 8$ (a promotion focus) or views $\$ 8$ as a $\$ 2$ loss to $\$ 10$ (a prevention focus). However, in interdependent contexts where relative outcomes are also available to consider, we expect 
individuals' decisions will be guided by preferences for absolute outcomes when in a promotion focus, and by preferences for relative outcomes when in a prevention focus.

\section{Promotion Focus and Absolute Outcomes}

When making an interdependent decision, individuals with a promotion focus will primarily consider absolute economic outcomes because they focus on advancement and opportunity. Previous research suggests that individuals with a promotion focus do not want to "miss out" on opportunities to make progress toward desired results (Crowe \& Higgins, 1997). Thus, such individuals should be concerned with obtaining as much as they can. Having more absolute economic outcomes allows individuals to obtain more ends and access more opportunities (e.g., to purchase any item on eBay). Any amount of money that is forsaken in order to increase one's relative outcomes compared to another person-for example, accepting $\$ 8$ instead of $\$ 10$ in the interdependent situation described above-represents missed opportunities that could have been pursued with that money.

Whereas increasing absolute outcomes create a range of additional opportunities, the opportunities gained by increasing relative outcomes are more restricted. The vast majority of the time, having more money than another person serves a purely symbolic value, i.e., as a signal of status, which we elaborate on below, without presenting any tangible opportunities. Having more than another person has advantages primarily in instances where one tries to outbid the other party over the same end (e.g., to buy the same item on eBay), which are likely to be rare. Thus, relative outcomes are unlikely to be seen as an opportunity to acquire more desired ends. In sum, individuals in a promotion focus should be more concerned with absolute outcomes than relative outcomes, because probabilistically absolute outcomes offer more potential opportunities.

\section{Prevention Focus and Relative Outcomes}


Individuals in a prevention focus are expected to be more concerned than those in a promotion focus with relative outcomes when making interdependent economic decisions. These individuals are concerned with security and safety, and, consequently, are strongly motivated to secure themselves against any possibility of loss (Friedman, 1999; Roese, Hur, \& Pennington, 1999). For example, there are multiple routes to secure a house (e.g., lock the doors and windows, set the alarm, and tell the neighbors you'll be away). To ensure their house is safe, individuals in a prevention focus will ensure that no possible route is left unsecured (Friedman, 1999). Similarly, although competition with another party over the same end is probabilistically rare, leaving such a possibility open is analogous to leaving a single door in one's house unlocked. Therefore, individuals in a prevention focus might reject options with disadvantageous relative outcomes (i.e., self gets $\$ 10$, other gets $\$ 12$ ) despite the opportunities presented by its greater absolute value, because such an option leaves open the possibility of loss.

Colloquially, an individual's relative advantage or disadvantage compared to others is known as "status" (Adams, 1965; Tajfel \& Turner, 1986), defined by Merriam-Webster (2012) as a "position or rank in relation to others". In contrast to value determined through absolute measures, status implies that one's value and importance are relative. For these reasons, although individuals in a prevention focus may not be more prosocial, they may be more concerned with socially defined, or relative, value -- i.e., status (cf., Zhang, Higgins, \& Chen, 2011). We propose that the concern with status will cause individuals in a prevention focus to be willing to sacrifice absolute gains and opportunities to avoid relative disadvantage.

The connection between prevention focus and concerns with status has not been previously tested, but some evidence supports this link. Oyserman, Uskul, Yoder, Nesse, and Williams (2007) found that making participants' stigmatized social category membership salient 
made them more prevention-focused. They also found that participants primed with a prevention focus were more likely than those primed with a promotion focus to interpret an ambiguous situation (i.e., receiving a negative performance review) as involving unfair social treatment (i.e., racial discrimination). Because perceptions of unfair social treatment are driven in part by concerns with low social status (Crocker, Major, \& Steele, 1998; Leonardelli \& Tormala, 2003), it is reasonable to extrapolate from this research that a prevention focus might also lead to stronger concerns with status than a promotion focus. That is, low social status, like stigmatization, may similarly be associated with vigilance and prevention.

In sum, we predict that, when making interdependent economic decisions, individuals in a promotion focus will be more concerned with absolute outcomes whereas those in a prevention focus will be more concerned with relative outcomes. We tested our theory in three studies, using different interdependent decision-making contexts.

Study 1: The Ring Measure

The most direct way to test our theory is to test how regulatory focus influences interdependence orientations (Messick \& McClintock, 1968), which refer to individuals' intentions or goals with interdependence. Interdependence orientations have been investigated across domains - including social dilemmas (e.g., Messick \& McClintock, 1968), intergroup relations (e.g., Tajfel, Billing, Bundy, \& Flament, 1971), and negotiations (e.g., De Dreu \& Van Lange, 1995). This research reveals that four orientations are typically exhibited (Bornstein et al., 1983; Brewer \& Silver, 1978; Eek \& Garling, 2006; Knight \& Dubro, 1984; Tajfel et al., 1971; Van Lange, 1999): equality (i.e., to minimize differences in outcomes), joint gain (i.e., to maximize total value for both parties), relative gain (i.e., to maximize own outcome over other party), and self gain (i.e., to maximize own outcome). Although these orientations are usually 
classified as prosocial (equality, joint gain) or proself (relative gain, self gain), they can also be classified as focusing on outcomes that are relative (relative gain, equality) or absolute (self gain, joint gain; see Table 1). We refer to this second dimension as "economic orientation."

We used a well-validated measure to identify the interdependence orientation that one most consistently exhibits — the ring measure (Griesinger \& Livingston, 1973; Liebrand, 1984)— and we expected individuals in a promotion focus would be more likely to exhibit absolute orientations and those in a prevention focus would be more likely to exhibit relative orientations.

\section{Method}

University of Toronto undergraduates $(N=184)$ participated for course credit or $\$ 5$. Participants were seated at computers and told they would be completing an online decisionmaking task with other participants. As the program was supposedly establishing a network connection with the other participants, the actual participants were asked to complete an ostensibly unrelated essay task, which was the regulatory focus manipulation (similar to Higgins Roney, Crowe, \& Hymes, 1994). Students were asked to write about an academic goal and were randomly assigned to write about either "the negative and goal-obstructing things and behaviors you will avoid to realize this goal" (prevention) or "the positive and goal-facilitating things and behaviors you will approach to realize this goal" (promotion). After the regulatory focus manipulation, participants reported whether they planned to complete the resource allocation task by "approaching positivity" (a promotion strategy) or "avoiding negativity" (a prevention strategy). The participants who answered inconsistently with their experimental conditions were asked to re-complete the manipulation until they answered correctly.

Participants then completed the ring measure: they evaluated which payoff in a series of 24 payoff pairs they preferred. Each payoff represented a pair of "self" and "other" outcomes. 
payoffs were generated from a circle on a self-other outcome plane, defined by orthogonal dimensions of self-outcome and other-outcome (Figure 1; for more details, see Van Lange, 1999). All participants reported that they understood the ring measure's instructions.

To identify each participant's dominant orientation, a k-means cluster analysis (Knight \& Dubro, 1984) was used. Because participants' choice on any given pair of payoffs could be a function of multiple orientations, the responses on the 24 payoff pairs were summarized into five indices that represent the extent to which the participant's responses consistently exhibited self gain, joint gain, equality, relative gain, and altruism ${ }^{l}$. These measures could range from -1 to 1 , where 1 meant the orientation was exhibited consistently (van Lange, 1999). However, these indices, although conceptually distinct, were derived from the same payoff and thus were sometimes artificially associated with each other. For example, even though self gain and relative gain are theoretically and empirically distinct, for more than half of the 24 payoff pairs, the participant would have chosen the same response. To address these mathematical artifacts, we submitted participants' responses on the five indices to a k-means cluster analysis, classifying participants based on how well their responses conformed to the ideal response pattern dictated by each of the five orientations. For example, exhibiting pure relative gain would yield an ideal response pattern as follows: relative gain index $=1$, self gain index $=.71$, equality index $=0$, joint gain index $=0$, and altruism index $=-.71$. Participants whose responses more closely conformed to this pattern than to the patterns dictated by the other four orientations were classified as exhibiting relative gain.

\section{Results and Discussion}

\footnotetext{
${ }^{1}$ Altruism, defined as maximizing only other party's outcomes, is rarely observed in previous research, but we included it in the analysis to allow participants' responses to be classified as altruistic.
} 
Consistent with previous research (e.g., Eek \& Garling, 2006), most participants (183/184 $=99 \%$ ) exhibited equality, joint gain, relative gain or self gain (Table 2); only one exhibited altruism and was excluded from the analyses.

Because orientation responses are dependent on one another (the responses for three orientations determine responses for the fourth), it was necessary to conduct a series of binary logistic regression analyses using the relative frequency of the four orientations (Cohen, Cohen, West, \& Aiken, 2003; Fox, 1997). We first examined whether regulatory focus predicted differences in social orientation and then tested whether it predicted economic orientation within each social orientation. Interdependence orientations were classified as prosocial $(0)$ or proself (1). Regulatory focus did not predict social orientation, $b=-.14, p=.65, r_{\text {equiv }}=.06$.

Of those with prosocial orientations, responses were then classified as equality (0) or joint gain (1); analysis revealed that equality was exhibited more by individuals with a prevention focus $\left(20 / 34=58.8 \% ; C I_{95 \%}=42.3 \%, 75.6 \%\right)$ than promotion focus $(12 / 40=30 \%$; $C I_{95 \%}=15.8 \%, 44.2 \%$; Table 2$), b=1.20, p=.014, r_{\text {equiv }}=.28$. Of those with proself orientations, responses were classified as relative gain (0) or self gain (1); analysis revealed that relative gain was exhibited significantly more by those with a prevention focus $(25 / 56=44.6 \%$; $\left.C I_{95 \%}=31.6 \%, 56.7 \%\right)$ than promotion focus $\left(7 / 53=16.4 \% ; C I_{95 \%}=4.0 \%, 22.3 \%\right.$; Table 2$), b=-$ $1.67, p<.001, r_{\text {equiv }}=.31$. Consistent with predictions, Study 1 revealed that individuals with a promotion focus preferred absolute orientations and those with a prevention focus preferred relative orientations.

Study 2: Multiple Alternative Matrices

The second study was conducted to replicate Study 1 with a different manipulation of regulatory focus and a new measure that assesses multiple orientation preferences 
simultaneously. We expected a promotion focus to yield a preference for absolute orientations, and a prevention focus to yield a preference for relative orientations. Treating economic orientation as a within-participant factor, regulatory focus was expected to interact with economic orientation to predict orientation preferences.

Furthermore, we explored whether our predictions would manifest in ways that were consistent with participants' social motivation. Although we expected the interaction between regulatory focus and economic orientation to occur regardless of an individual's social motivation, we expected the predicted interaction to manifest on joint gain and equality when individuals are motivated to be prosocial, but to manifest on self gain and relative gain when they are motivated to be proself. In the context of the current study's mixed design - which consisted of between-participant manipulations of regulatory focus (promotion, prevention) and social motivation (to be prosocial, to be proself), and within-participant preference measures for social orientations (prosocial, proself) and economic orientations (absolute, relative) - this prediction would be indicated by a four-way interaction.

\section{Method}

University of Toronto undergraduates $(N=134)$ participated for course credit. They first completed a regulatory focus manipulation (Lockwood, Jordan, \& Kunda, 2002) in which they were presented a list of 36 words (randomly ordered) and were asked to categorize the words into three categories. Twelve words were fruit-related and twelve animal-related. The final 12 words were related to either promotion (e.g., gain, achieve) or prevention (e.g., avoid, prevent) depending on the priming condition. All participants completed the regulatory focus manipulation correctly. 
Participants then read an ostensibly unrelated scenario: They have purchased a computer from a salesperson and found out that it came with a rebate, and now, they needed to negotiate with the salesperson to divide the rebate. We manipulated participants' motivation to be prosocial or proself by telling participants the salesperson was either helpful (prosocial) or rude (proself; Loewenstein et al., 1989).

The four interdependent orientations were explained to participants with descriptions and payoff examples (Bornstein et al., 1983): self gain (47 for self, 30 for other), relative gain (42 for self, 22 for other), joint gain (44 for self, 36 for other), and equality (34 for self, 34 for other). They reported their a) preference for and b) intention to adopt each orientation using a 7-point scale (1=not at all, 7=very much; Gaertner \& Insko, 2000). Internal consistencies were acceptable $(.70<\alpha \mathrm{s}<.85)$. The two items were averaged for each orientation. Higher scores indicated stronger preference.

\section{Results and Discussion}

The salesperson manipulation successfully affected social motivation: prosocial orientations (averaged together) were preferred more when the salesperson was helpful $(M=4.86$, $S D=1.22)$ than rude $(M=3.71, S D=1.22)$, and proself orientations were preferred more when the salesperson was rude $(M=4.92, S D=1.14)$ than helpful $(M=4.00, S D=1.59)$, both $t s>3.80$, ps $<.001, r_{\text {equiv }}>.31$.

Interdependence orientation scores were submitted to a repeated-measure ANOVA with regulatory focus and social motivation as between-participant factors, and social orientation and economic orientation as within-participant factors. As predicted, analysis revealed a four-way interaction, $F(1,130)=23.30, p<.001, r=.39$ (see Table 3 for means). Probing this interaction further, analysis of participants in the helpful condition revealed a three-way interaction between 
regulatory focus, economic orientation, and social orientation, $F(1,130)=18.46, p<.001, r=.44$. Further analysis indicated that the regulatory focus by economic orientations interaction was significant for prosocial orientations (joint gain, equality), $F(1,130)=26.03, p<.001, r=.47$. Individuals exhibited a greater preference for joint gain when in a promotion than prevention focus, $F(1,130)=8.06, p=.005, r=.17$, but a greater preference for equality when in a prevention than promotion focus, $F(1,130)=19.14, p<.001, r=.27$. The regulatory focus by economic orientation interaction was not significant for proself orientations, $F<1$.

Similar analyses were conducted for the rude condition, revealing a three-way interaction between regulatory focus, economic orientation, and social orientation, $F(1,130)=7.00, p=.009$, $r=.35$. The regulatory focus by economic orientations interaction contrast was significant for proself orientations (self gain, relative gain), $F(1,130)=17.95, p<.001, r=.48$. Individuals exhibited a greater preference for self gain when in a promotion than prevention focus, $F(1,130)=9.18, p=.003, r=.19$, but a greater preference for relative gain when in a prevention than promotion focus, $F(1,130)=8.77, p=.003, r=.18$. The regulatory focus by economic orientation interaction and regulatory focus main effect were not significant for prosocial orientations, $F \mathbf{s}<1.74, p s>.18$.

Study 2 replicated Study 1: When being prosocial, individuals in a promotion focus preferred joint gain and those in a prevention focus preferred equality; When being proself, individuals in a promotion focus preferred self gain and those in a prevention focus preferred relative gain. Now that the first two studies firmly established a connection between regulatory focus and interdependent orientation, the next study explored whether regulatory focus affects people's preference for real economic outcomes.

Study 3: Ultimatum Game 
In Study 3, we presented participants with a real economic offer in a highly controlled context - the ultimatum game (Guth, et al., 1982). The offer had positive absolute value (participants would get $\$ 1$ ) but poor relative standing (the other party would get \$9). Accepting the offer thus represented a preference for absolute over relative outcomes whereas rejecting the offer represented a preference for relative over absolute outcomes. We predicted that a prevention focus would lead to higher rejection rates than a promotion focus. We also tested our proposed mechanism for this effect, i.e., whether a prevention focus leads to greater concern with relative outcomes because of greater concern with status.

\section{Method}

University of Toronto undergraduates $(N=51)$ participated for $\$ 3$. The experiment consisted of a regulatory focus (prevention, promotion) between-participant design. Participants were randomly assigned to one of two lab rooms. All participants completed a regulatory focus manipulation in which they wrote an essay about the hopes, aspirations, and accomplishments that they would ideally like to achieve (promotion) or the duties, obligations, and responsibilities they felt they ought to meet (prevention).

Afterward, participants completed an ostensibly unrelated task: the ultimatum game. In this game, a "proposer" chooses how to divide $\$ 10$ between two parties. A "responder" decides whether to accept or reject it. If accepted, both parties receive the actual payoff; if rejected, both receive nothing. The participants in both rooms were told that they were randomly assigned to the responder role and therefore the participants in the other room were the proposers. Each participant was then given a hand-written offer proposing that the responder (the participant) receive $\$ 1$ and the proposer receive $\$ 9$. The participants accepted or rejected the offer 
(rejection $=1$, acceptance $=0$ ) and then were compensated (and awarded an extra $\$ 1$ if they accepted the offer) and debriefed.

Before responding to the offer, participants reported their concern with status on the following 5-item measure (1=not at all, 5=extremely):"I feel that I am valued as a person by the proposer (Reverse-scored)"; "I feel that I am appreciated as an individual by the proposer (Reverse-scored)"; "I feel that the proposer is treating me as an important individual (Reversescored)"; "I feel that I am respected as a person by the proposer (Reverse-scored)"; "I feel that the proposer is not taking me seriously". The first two items were adapted from Grant \& Gino's (2010) social worth scale and the rest were created for the purpose of this study $(\alpha=.77)$. An exploratory factor analysis with oblimin rotation yielded a one-factor solution: all five items loaded onto a single factor. This suggests that although social worth and status are not synonymous, Grant and Gino's social worth items and our status items converge on a similar construct. Thus, the five items were averaged together into a single "concern with status" index. Higher scores indicated greater concern with status.

\section{Results and Discussion}

A logistic regression analysis of offer rejection revealed a significant regulatory focus (prevention $=0$, promotion $=1$ ) effect, $b=-1.49, p=.019, r_{\text {equiv }}=.15$. Offers were rejected more by those in a prevention focus $(12 / 25=48.0 \%)$ than promotion focus $(5 / 29=17.2 \%)$. We also conducted an ANOVA to test for regulatory focus differences in concern with status. Individuals in a prevention focus were more concerned with status $(M=4.33, S D=.57)$ than those in a promotion focus $(M=3.63, S D=1.21), t(52)=2.66, p=.01, r_{\text {equiv }}=.35$.

Standard procedures were followed to test mediation (Baron \& Kenny, 1986). First, a logistic regression analysis revealed that concern with status positively predicted offer rejection, 
$b=1.41, p=.012, r_{\text {equiv }}=.17$. Submitting offer rejection to a simultaneous analysis revealed that regulatory focus no longer predicted offer rejection, $b=-1.16, p=.089$, but concern with status remained a significant predictor, $b=1.36, p=.024, r_{\text {equiv }}=.15$. A bootstrap analysis (Preacher $\&$ Hayes, 2004; Shrout \& Bolger, 2002) revealed that the mediation was statistically significant, $b=-.95, C I_{95 \%}=(-3.22,-.067), 1,000$ bootstrap resamples (Figure 2).

Study 3 revealed that individuals in a prevention focus were more likely than those in a promotion focus to reject an offer with poor relative standing. Consistent with our rationale, we found that the concern with status was the driving mechanism behind our effect ${ }^{2}$.

\section{General Discussion}

Studies 1 and 2 demonstrated that a prevention focus leads to a stronger concern with relative outcomes than a promotion focus. Study 3 further demonstrated that individuals in a prevention focus were more likely than those in a promotion focus to sacrifice absolute gain to avoid a negative relative outcome in an ultimatum game. These findings were consistent across different operationalizations of regulatory focus and economic orientation. Also, Study 3 provided evidence for the mechanism linking prevention focus to concerns with relative outcomes. Individuals in a prevention focus were more likely than those in a promotion focus to reject the offer because they were more concerned with the low status the offer represented.

\footnotetext{
${ }^{2}$ To add confidence to the link between regulatory focus and concern with status, we conducted a conceptual replication. Sixty-one participants completed the same regulatory focus manipulation used in Study 3 and then a projective test (Sokolowski, Schmalt, Langens, \& Puca, 2000). In this test, participants saw 14 pictures of various interactions (e.g., a man and a woman playing tennis) and indicated whether they believed at least one person in each interaction was concerned with status. Concern with status was calculated as the number of pictures participants indicated as status-related. Consistent with Study 3, a prevention focus led to a greater concern with status $(M=5.38, S D=2.81)$ than a promotion focus $(M=4.17, S D=1.78), b=.25, S E=.12$, Wald $\chi^{2}=4.56$, $p=.03$.
} 
We have built on existing theories for interdependent decision-making (Deutsch, 1973; Messick \& McClintock, 1968) to argue that regulatory focus reflects divergent means of pursuing self-interest, and thus affects the economic outcomes individuals pursue. Regardless of social motivation (prosocial or proself), a promotion focus leads to the pursuit of absolute economic outcomes and a prevention focus leads to the pursuit of relative outcomes. By exploring the motivational underpinnings of these economic orientations, our findings lead to the counterintuitive conclusion that two types of seemingly dissimilar relative orientations - equality, a prosocial orientation, and relative gain, a proself orientation -may ultimately serve the same self-regulatory purpose: the establishment of security.

This perspective also offers a different lens with which to view the negotiations research reported by Galinsky et al. (2005), in which a promotion focus led negotiators to focus on target price and achieve better personal and joint outcomes. Instead of suggesting that individuals in a prevention focus are more prosocial or less concerned with self-interest than those in a promotion focus, our findings suggest that the self-interest concerns of individuals in a promotion or prevention focus manifest in different forms - i.e., in distinct concerns with absolute or relative outcomes. Further, these findings suggest some additional consequences of regulatory focus that have not been previously explored within the domain of negotiations (Appelt, Zou, Arora, \& Higgins, 2009; Appelt \& Higgins, 2010). For example, because of their concern with relative outcomes, negotiators with a prevention focus may be more likely to make the potentially false fixed-pie assumption, in which negotiators assume that the more value they accumulate at the bargaining table, the less other party receives (Thompson \& Hastie, 1990).

Although we have argued that our findings are the result of regulatory focus differences in how individuals pursue self-interest, an alternative possibility is that there are regulatory focus 
differences in attention to fairness and social norms that are captured by concerns with equality and relative disadvantage. This explanation is supported by the evidence that individuals in a prevention focus are more concerned with social obligation (Higgins, 1997), have more interdependent self-construals (Lee, Aaker, \& Gardner, 2000), and are more likely to follow interpersonal norms established by others (Zhang et al., 2011). However, according to this explanation, such concerns should have led individuals in a prevention focus to demonstrate a prosocial orientation in our studies, which we did not find. Thus, although a concern with social norms may play a role in interdependent decision-making for those with prevention focus, we believe it is likely as a normative gauge for assessing one's own outcomes against some status quo - in this case, the other party's outcomes (Scholer, Zou, Fujita, Stroessner, Higgins, 2010). That is, an individual knows his or her outcome to be satisfactory as long as he or she has as much as or more value than another person.

Notably, our predictions are specific to the distribution of those resources that function to facilitate exchange rather than with resources that provide a use or service (DeVoe \& Iyengar, 2010). For example, money or frequent flyer miles are typically valued for what they can be traded for, but a coffee mug or an apple is typically valued for its use - to drink coffee or to eat. Our predictions are intended for resources with exchange value because it is with these resources that it is advantageous to maximize absolute value. After all, there are only so many apples that consumers will want to eat and store, whereas the acquisition of money can be valued indefinitely.

\section{Conclusion}

Traditional motivational theories of self-interest explain why individuals maximize absolute economic outcomes in interdependent economic decisions, but not why individuals 
make choices based on relative outcomes. In three studies, we found individuals' preferences for these two types of economic outcomes can be predicted by regulatory focus theory. Individuals in a prevention focus were attuned to relative outcomes, whereas those in a promotion focus were attuned to absolute outcomes. Understanding how decisions about relative versus absolute outcomes may be linked to motivational concerns with security versus advancement may help us understand the reasons why relative orientations may manifest in both individuals and groups. Interestingly, our findings demonstrate that preferences for both relative advantage and equality may be driven by concerns with security. 
References

Adams, S. J. (1965). Inequity in social exchange. In Derkowitz, L. (Ed.) Advances in Experimental Social Psychology, 2, 267-299, Academic Press, New York.

Appelt, K. C. \& Higgins, E. T. (2010). My way: how strategic preferences vary by negotiator role and regulatory focus. Journal of Experimental Social Psychology. 46, 1138-1142. doi:10.1016/j.jesp.2010.05.010

Appelt, K. C., Zou, X., Arora, P., \& Higgins, E. T. (2009). Regulatory fit in negotiation: effects of “prevention-buyer” and “promotion-seller” fit. Social Cognition. 27(3), 365-384. doi:10.1521/soco.2009.27.3.365

Baron, R. M., \& Kenny, D. A. (1986). The Moderator-Mediator Variable Distinction in Social Psychological Research: Conceptual, Strategic, and Statistical Considerations. Journal of Personality and Social Psychology, 51(6), 1173-1182. doi:10.1037//0022-3514.51.6.1173

Bohns, V. K., Lucas, G. M., Molden, D. C., Finkel, E. J., Coolsen, M. K., Kumashiro, M., Rusbult, C. E. \& Higgins, E. T. (in press). Opposites fit: Regulatory focus complementarity and relationship well-being. Social Cognition.

Bornstein, G., Crum, L., Wittenbraker, J., Harring, K., Insko, C. A., \& Thibaut, J. W. (1983). On the measurement of social orientations in the minimal group paradigm. European Journal of Social Psychology, 13, 321-350. doi:10.1002/ejsp.2420130402

Brewer, M. B., \& Silver, M. (1978). Ingroup bias as a function of task characteristics. European Journal of Social Psychology, 8, 393-400. doi:10.1002/ejsp.2420080312 
Brockner, J., Paruchuri, S., Idson, L. C., \& Higgins, E. T. (2002). Regulatory focus and the probability estimates of conjunctive and disjunctive events. Organizational Behavior and Human Decision Processes, 87(1), 5-24. doi:10.1006/obhd.2000.2938

Carnevale, P. J. \& De Dreu, K. W. (2006). Motive: The negotiator's raison detre. In L. L. Thompson (Ed.), Negotiation Theory and Research (pp. 55-76). New York, NY, USA: Psychology Press.

Cohen, J., Cohen, P., West, S. G., \& Aiken, L. S. (2003). Applied Multiple Regression/Correlation Analysis for the Behavioral Sciences (3rd ed.). Mahwah, NJ: Erlbaum.

Crocker, J., Major, B., \& Steele, C. (1998). Social stigma. In D. T. Gilbert \& S. T. Fiske (Eds.), Handbook of social psychology (Vol. 2, fourth ed., pp. 504-553). New York: McGrawHill.

Crosby, F. (1976). A model of egoistical relative deprivation. Psychological Review, 83, 85-113. doi:10.1037//0033-295X.83.2.85

Crowe, E., \& Higgins, E. T. (1997). Regulatory focus and strategic inclinations: Promotion and prevention in decision making. Organizational Behavior and Human Decision Processes, 69, 117-132. doi:10.1006/obhd.1996.2675

De Dreu, C. K. W., \& Van Lange, P. A. M. (1995). The impact of social value orientations on negotiator cognition and behavior. Personality and Social Psychology Bulletin, 21(11781188). doi:10.1177/01461672952111006 
Deutsch, M. (1973). The resolution of conflict: Constructive and destructive processes. New Haven: Yale University Press.

DeVoe, S. E., \& Ivengar, S. S. (2010). The medium of exchange matters: What's fair for goods is unfair for money. Psychological Science, 21, 159-162. doi:10.1177/0956797609357749

Eek, D., \& Garling, T. (2006). Prosocial prefer equal outcomes to maximizing joint outcomes. British Journal of Social Psychology, 45(2), 321-337. doi:10.1348/014466605X52290

Festinger, L. (1954) A theory of social comparison processes, Human Relations 7, 117-40 doi: $10.1177 / 001872675400700202$

Fox, J. (1997). Applied regression analysis, linear models, and related methods. Thousand Oaks, CA: Sage.

Friedman, R. S. (1999). The phenomenological correlates and consequences of distinct selfregulatory systems. Unpublished dissertation. Columbia University.

Gaertner, L. \& Insko, C. A. (2000). Intergroup discrimination in the minimal group paradigm: Categorization, reciprocation, or fear? Journal of Personality and Social Psychology, 79, 77-94. doi:10.1037//0022-3514.79.1.77

Galinsky, A. D., Leonardelli, G. J., Okhuysen, G. A., \& Mussweiler, T. (2005). Regulatory Focus at the Bargaining Table: Promoting Distributive and Integrative Success. Personality and Social Psychology Bulletin, 31(8), 1087-1098. doi:10.1177/0146167205276429 
Grant, A. M. \& Gino, F. (2010). A little thanks goes a long way: explaining why gratitude expressions motivate prosocial behavior. Journal of Personality and Social Psychology, 98(6), 946-955. doi:10.1037/a0017935

Griesinger, D. W., \& Livingston, J. W. (1973). Toward a model of interpersonal orientation in experimental games. Behavioral Science, 18, 173-188.

Guth, W., Schmittberger, R., \& Schwarze, B. (1982). An experimental analysis of ultimatum bargaining. Journal of Economic Behavior and Organization, 3, 367-388. doi:10.1016/0167-2681(82)90011-7

Hamner, W. C., \& Harnett, D. L. (1975). The effects of information and aspiration level on bargaining behavior. Journal of Experimental Social Psychology, 11, 329-342.

Higgins, E. T. (1997). Beyond pleasure and pain. American Psychologist, 52, 1280-1300. doi:10.1037//0003-066X.52.12.1280

Higgins, E. T., Roney, C. J. R., Crowe, E., \& Hymes, C. (1994). Ideal versus ought predilections for approach and avoidance: distinct self-regulatory systems. Journal of Personality and Social Psychology, 66(2), 276-286. doi:10.1037//0022-3514.66.2.276

Knight, G. P., \& Dubro, A. F. (1984). Cooperative, competitive, and individualistic social values: An individualized regression and clustering approach. Journal of Personality and Social Psychology, 46(1), 98-105. doi:10.1037//0022-3514.46.1.98

Lee, A. Y., Aaker, J. L., \& Gardner, W. L. (2000). The pleasures and pains of distinct selfconstruals: The role of interdependence in regulatory focus. Journal of Personality and Social Psychology, 78, 1122-1134. doi:10.1037//0022-3514.78.6.1122 
Leonardelli, G. J., \& Lakin, J. L. (2010). The new adventures of regulatory focus: Selfuncertainty and the quest for diagnostic feedback. In R. M. Arkin, K. C. Oleson \& P. J. Carroll (Eds.). The uncertain self: A handbook of perspectives from social and personality psychology. Mahwah, NJ, USA: Lawrence Erlbaum Associates, Inc.

Leonardelli, G. J., Lakin, J. L., \& Arkin, R. M. (2007). A regulatory focus model of selfevaluation. Journal of Experimental Social Psychology, 43(6), 1002-1009. doi:10.1016/j.jesp.2006.10.021

Leonardelli, G. J., \& Tormala, Z. L. (2003). The negative impact of perceiving discrimination on collective well-being: The mediating role of perceived ingroup status. European Journal of Social Psychology, 33, 507-514.

Liberman, N., Idson, L. C., Camacho, C. J., \& Higgins, E. T. (1999). Promotion and prevention choices between stability and change. Journal of Personality and Social Psychology, 77, 1135-1145. doi:10.1037//0022-3514.77.6.1135

Liebrand, W. B. G. (1984). The effect of social motives, communication and group size on behavior in an N-person multi-stage mixed-motive game. European Journal of Social Psychology, 14, 239-264. doi:10.1002/ejsp.2420140302

Lockwood, P., Jordan, C. H., \& Kunda, Z. (2002). Motivation by positive or negative role models: Regulatory focus determines who will best inspire us. Journal of Personality and Social Psychology, 83(4), 854-864. doi:10.1037//0022-3514.83.4.854 
Loewenstein, G. F., Thompson, L., \& Bazerman, M. H. (1989). Social utility and decision making in interpersonal contexts. Journal of Personality and Social Psychology, 57(3), 426-441. doi:10.1037//0022-3514.57.3.426

Messick, D. M., \& McClintock, C. G. (1968). Motivational bases of choice in experimental games. Journal of Experimental Social Psychology, 4(1), 1-25. doi:10.1016/0022$\underline{1031(68) 90046-2}$

Messick, D. M., \& Thorngate, W. B. (1967). Relative gain maximization in experimental games. Journal of Experimental Social Psychology, 3(1), 85-101. doi:10.1016/0022$\underline{1031(67) 90039-X}$

Mill, J. S. (1874/1968). Essays on some unsettled questions of political economy (2nd ed.). New York: Augustus M. Kelley Publishers.

Oishi, S., Kesebir, S., \& Diener, E. (2011). Income inequality and happiness. Psychological Science, 22(9), 1095-1100. doi:10.1177/0956797611417262

Oyserman, D., Uskul, A., Yoder, N., Nesse, R., \& Williams, D (2007).Unfair treatment and selfregulatory focus. Journal of Experimental Social Psychology, 43, 505-512.

Preacher, K. J., \& Hayes, A. F. (2004). SPSS and SAS procedures for estimating indirect effects in simple mediation models. Behavior Research Methods Instruments \& Computers, 36, 717-731. doi:10.3758/BF03206553

Pruitt, D. G., \& Rubin, J. Z. (1986). Social conflict: Escalation, stalemate, and settlement. New York: Random House. 
Roese, N. J., Hur, T., \& Pennington, G. L. (1999). Counterfactual thinking and regulatory focus: Implications for action versus inaction and sufficiency versus necessity. Journal of Personality and Social Psychology, 77(6), 1109-1120. doi:10.1037//0022-3514.77.6.1109

Sassenberg, K., \& Woltin, K-A. (2008). Group-based self-regulation: The effects of regulatory focus. European Review of Social Psychology, 19, 126-164.

Scheepers, D., Spears, R., Doosje, B., \& Manstead, A. S. R. (2006). The social functions of ingroup bias: Creating, confirming, or changing social reality. European Review of Social Psychology, 18, 359 - 396. doi:10.1080/10463280601088773

Scholer, A. A. \& Higgins, E. T. (2011). Promotion and prevention systems: regulatory focus dynamics within self-regulatory hierarchies. In K. D. Vohs, \& R. Baumeister (Eds). Handbook of self-regulation: research, theory, and application (pp. 143-161). New York, NY: Guilford Press.

Scholer, A. A., Zou, X., Fujita, K., Stroessner, S. J., \& Higgins, E. T. (2010). When risk seeking becomes a motivational necessity. Journal of Personality and Social Psychology. 99(2), 215-231. doi:10.1037/a0019715

Shah, J. Y., Brazy, P. C., \& Higgins, E. T. (2004). Promoting us or preventing them: Regulatory focus and the nature of in-group bias. Personality and Social Psychology Bulletin, 30, 433-446.

Shrout, P. E., \& Bolger, N. (2002). Mediation in experimental and nonexperimental studies: New procedures and recommendations. Psychological Methods, 7(4), 422-445.

doi:10.1037//1082-989X.7.4.422 
Siegel, S., \& Fouraker, L. E. (1960). Bargaining and group decision making: experiments in bilateral monopoly. New York, NY: McGraw-Hill.

Snidal, D. (1991). Relative gains and the pattern of international cooperation. American Political Science Review, 85, 701-726.

Sokolowski, K., Schmalt, H, Langens, T. \& Puca, R. M. (2000). Assessing achievement, affiliation, and power motives all at once. Journal of Personality Assessment, 74(1), 126145. doi:10.1207/S15327752JPA740109

Status. (2012). In Merriam-Webster's online dictionary. Retrieved July 19, 2012, from http://www.merriam-webster.com/dictionary/status

Stouffer, S. A., Schuman, E. A., DeVinney, L. C., Star, S. A. \& Williams, R. B. (1949). The American Soldier: Adjustment During Army Life, Volume 1. Princeton University Press.

Suls, J., \& Wheeler, L. (Eds.). (2000). Handbook of social comparison: Theory and research. New York: Kluwer Academic/Plenum Publishers.

Tajfel, H., Billing, M., Bundy, R., \& Flament, C. (1971). Social categorization and intergroup behavior. European Journal of Social Psychology, 1, 149-178. doi:10.1002/ejsp.2420010202

Tajfel, H. and Turner, J. C. (1986). The social identity theory of inter-group behavior. In S. Worchel and L. W. Austin (eds.), Psychology of Intergroup Relations. Chigago: NelsonHall.

Thompson, L., \& Hastie, R. (1990). Social perception in negotiation. Organizational Behavior and Human Decision Process, 47(1), 98-123. doi:10.1016/0749-5978(90)90048-E 
Trawalter, S., \& Richeson, J. A. (2006). Regulatory focus and executive function after interracial interactions. Journal of Experimental Social Psychology, 42, 406-412.

Turner, J. C. (1975). Social comparison and social identity: Some prospects for intergroup behaviour. European Journal of Social Psychology, 5(1), 5-34. doi:10.1002/ejsp.2420050102

Van Lange, P. A. (1999). The pursuit of joint outcomes and equality in outcomes: An integrative model of social value orientation. Journal of Personality and Social Psychology, 77(2), 337-349. doi:10.1037//0022-3514.77.2.337

Waltz, K. (1979). Theory of international politics. New York: Random House.

Zhang, S., \& Higgins, E. T., \& Chen, G. Q. (2011). Managing others like you were managed: How prevention focus motivates copying interpersonal norms. Journal of Personality and Social Psychology, 100, 647-663. doi:10.1037/a0021750 
Table 1

A Framework for Interdependence Orientations Organized by Social Orientation (Prosocial, Proself) and Economic Orientation (Relative, Absolute)

\begin{tabular}{ccc}
\hline & Relative & Absolute \\
\hline Prosocial & Equality & Joint Gain \\
Proself & Relative Gain & Self Gain \\
\hline
\end{tabular}


Table 2

Interdependence Orientations by Regulatory Focus: Study 1

\begin{tabular}{cccc}
\hline & Prevention & Promotion & Total \\
\hline Equality & $\mathbf{2 0}(\mathbf{2 2 \%})$ & $12(12.9 \%)$ & $32(17.4 \%)$ \\
Relative gain & $\mathbf{2 5}(\mathbf{2 7 . 5 \% )}$ & $7(7.5 \%)$ & $32(17.4 \%)$ \\
Joint gain & $14(15.4 \%)$ & $\mathbf{2 8}(\mathbf{3 0 . 1 \%})$ & $42(22.8 \%)$ \\
Self gain & $31(34.1 \%)$ & $\mathbf{4 6}(\mathbf{4 9 . 5 \% )}$ & $77(41.8 \%)$ \\
Altruism & $1(1.1 \%)$ & $0(0 \%)$ & $1(.6 \%)$ \\
Total & $91(100.0 \%)$ & $93(100.0 \%)$ & $184(100.0 \%)$ \\
\hline
\end{tabular}

Note. Frequencies presented (percentages within parentheses). Each bolded cell indicates the regulatory focus condition that elicited a more frequent manifestation of the interdependence orientation in a given row. Rounding error may prevent percentages from adding to $100 \%$. 
Table 3

Interdependence Orientation Scores By Regulatory Focus and Social Motivation: Study 2

$$
\text { Helpful Rude }
$$

Prevention Promotion Prevention Promotion

\begin{tabular}{|c|c|c|c|c|c|}
\hline \multirow{4}{*}{ Prosocial } & Equality & $5.23^{\mathrm{a}}$ & $3.99^{b}$ & $3.27^{b}$ & $3.69^{b}$ \\
\hline & & (.99) & (1.81) & (1.87) & $(1.76)$ \\
\hline & Joint gain & $4.75^{\mathrm{b}}$ & $5.56^{\mathrm{a}}$ & $3.62^{\mathrm{c}}$ & $4.26^{\mathrm{b}}$ \\
\hline & & (1.73) & (1.48) & $(1.87)$ & (1.78) \\
\hline \multirow{4}{*}{ Proself } & Relative gain & $3.17^{b}$ & $3.90^{b}$ & $5.12^{\mathrm{a}}$ & $4.21^{b}$ \\
\hline & & (1.48) & $(1.80)$ & (1.50) & $(1.31)$ \\
\hline & Self gain & $4.18^{b}$ & $4.55^{\mathrm{b}}$ & $4.72^{\mathrm{b}}$ & $5.65^{\mathrm{a}}$ \\
\hline & & $(1.90)$ & (1.77) & (1.68) & (1.23) \\
\hline
\end{tabular}

Note. Means presented (standard deviation is in parentheses). Each bolded score indicates the cell in each row that elicited the strongest interdependent orientation. Different superscripts in the same row indicate differences with $p<.05$. 
Figure Captions

Figure 1. Payoffs Sampled from the Self-Other Outcome Plane for the Ring Measure: Study 1.

Figure 2. Concern with Status as the Mediator between Regulatory Focus and Offer Rejection: Study 3. 
Figure 1

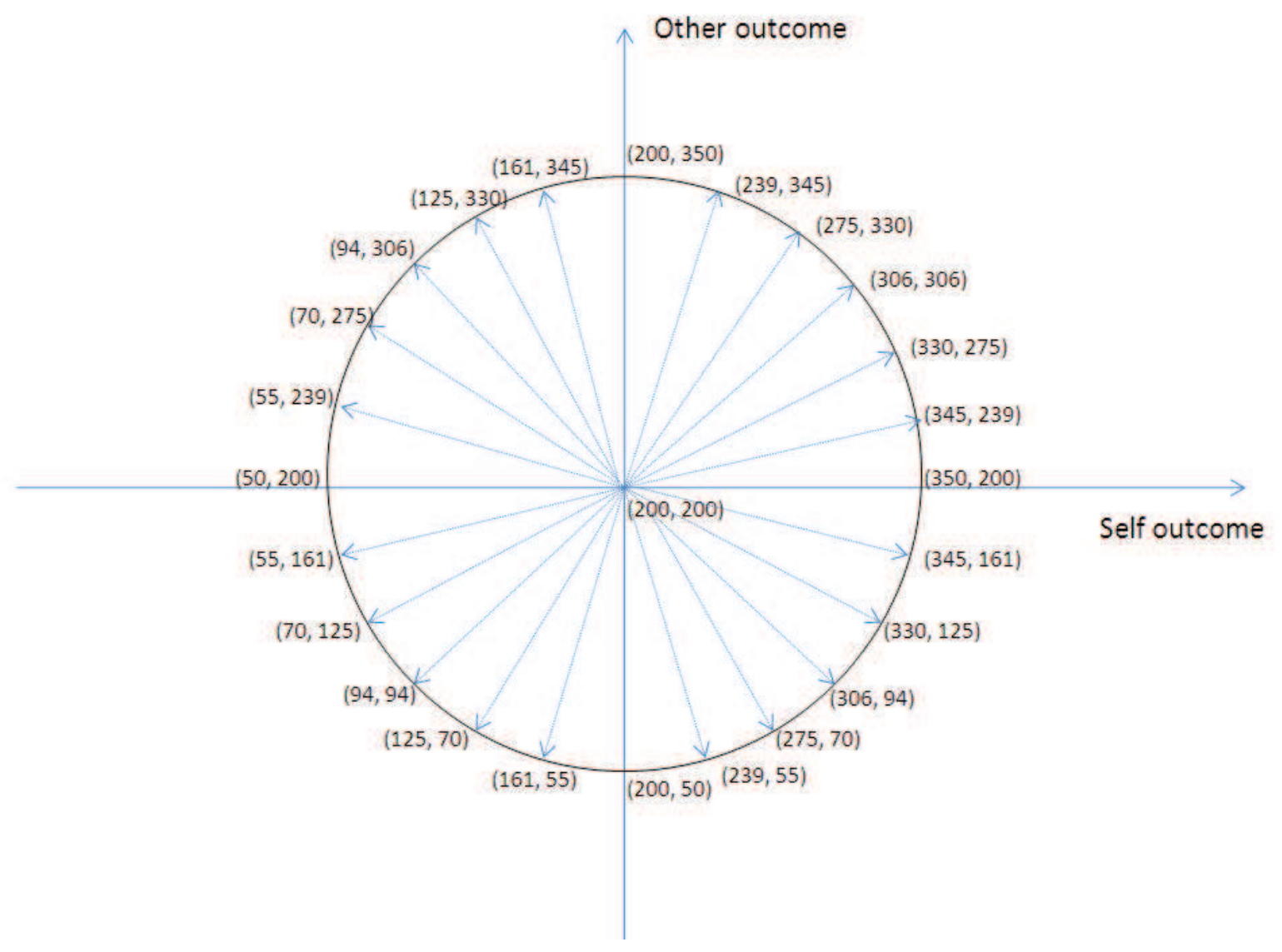

Note. Adjacent pairs of payoffs were used to create the 24 decomposed games from which individuals selected their preferred payoffs. For example, for one of the games, participants chose between giving themselves 350 and the other party 200 (first option) and giving themselves 345 and the other party 239 (second option). In another game, participants chose between giving themselves 350 and the other party 200 (first option) and giving themselves 345 and the other party 161 (second option). All 24 adjacent pairs were used in the creation of the 24 decomposed games. The center of the circle (200 to self, 200 to other) was not used in any of the games, and is included in the figure for reference purposes only. 
Figure 2

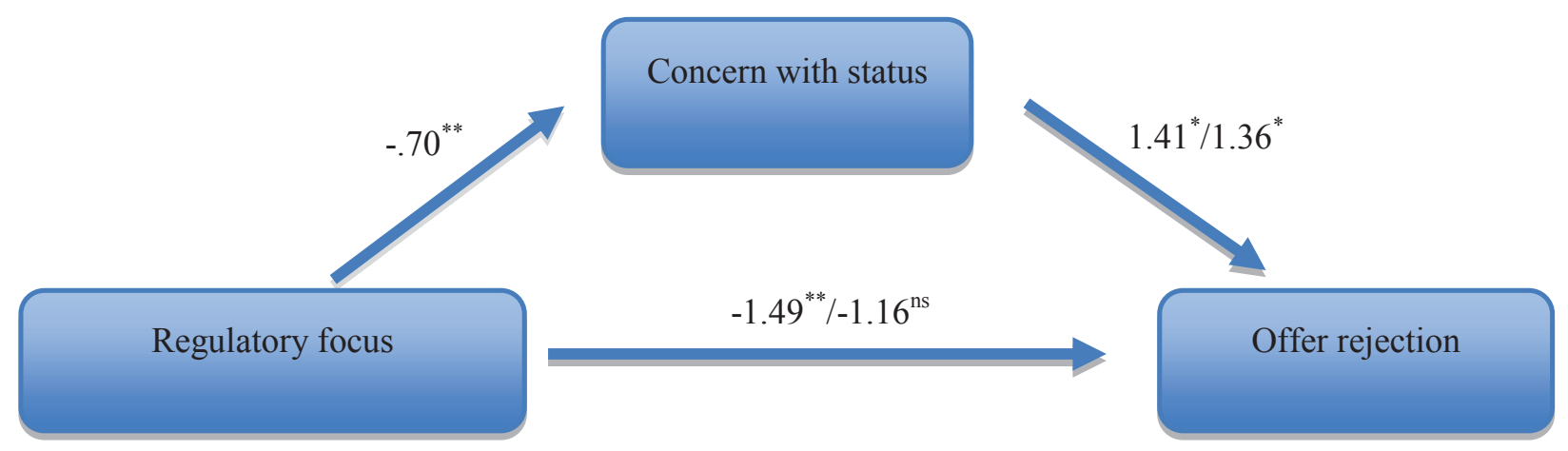

Note. Numbers represent unstandardized regression coefficients. ${ }^{*} p<.05 .{ }^{* *} p<.01 .{ }^{* * *} p<.001$. 